\title{
Mendeley readership altmetrics for the social sciences and humanities: Research evaluation and knowledge flows ${ }^{1}$
}

\author{
Ehsan Mohammadi, Mike Thelwall \\ E-mail: e.mohammadi@wlv.ac.ukm.thelwall@wlv.ac.uk \\ Statistical Cybermetrics Research Group, School of Technology, University of Wolverhampton, Wulfruna \\ Street, Wolverhampton WV1 1LY, UK.
}

\begin{abstract}
Although there is evidence that counting the readers of an article in the social reference site, Mendeley, may help to capture its research impact, the extent to which this is true for different scientific fields is unknown. This study compares Mendeley readership counts with citations for different social sciences and humanities disciplines. The overall correlation between Mendeley readership counts and citations for the social sciences was higher than for the humanities. Low and medium correlations between Mendeley bookmarks and citation counts in all the investigated disciplines suggest that these measures reflect different aspects of research impact. Mendeley data was also used to discover patterns of information flow between scientific fields. Comparing information flows based on Mendeley bookmarking data and cross disciplinary citation analysis for the disciplines revealed substantial similarities and some differences. Thus, the evidence from this study suggests that Mendeley readership data could be used to help capture knowledge transfer across scientific disciplines, especially for people that read but do not author articles, as well as giving impact evidence at an earlier stage than is possible with citation counts.
\end{abstract}

Keywords: Mendeley, beyond impact, altmetrics, Bookmarking data,

\footnotetext{
1 This is a preprint of an article to be published in the Journal of the American Society for Information Science and Technology @ copyright 2013 John Wiley \& Sons, Inc
} 


\section{Introduction}

Research evaluators often need to measure the impact of academic publications. Traditionally, librarians and information professionals have used re-shelving statistics to examine the value of scholarly artefacts (Blecic, 1999) but this is not useful for individual journal articles. Since the 1960s, citation indexes have been provided by the Institute for Scientific Information (ISI), now Thomson Reuters. These have led to significant changes in the investigation of scholarly commutation and research evaluation, primarily based on citation analysis. However, citation analysis is restricted to measuring the impact of publications from the author's perspective but an article could be useful for other contexts such as teaching, commercialisation, and daily working life (Schloegl \& Stock, 2004; Haustein \& Siebenlist, 2011). In particular, citation metrics are more appropriate for the evaluation of theoretical publications than for applied research. Moreover, there is a worry that a new generation of authors could believe that "citation analysis is a waste of time because authors do not adequately cite those who have influenced their work" (Garfield, 2011).

During the last decade, usage data have been proposed to help measure scientific impact and to supplement citation analysis (Rowlands \& Nicholas, 2005; Bollen, Van De Sompel, Smith, \& Luce, 2005; Schloegl \& Gorraiz, 2011). Concepts related to journal usage metrics have appeared with different terms such as "readership", "usage," and "downloads" in the literature (Kurtz \& Bollen, 2010). Journal usage metrics refer to indicators based on the usage data of electronic journals (Rowlands \& Nicholas, 2007) that provide reasonable evaluation of the journals (Hahn \& Faulkner, 2002), such as downloads or accesses. Similarly, readership has been defined as "full-text downloads" (Haque \& Ginsparg, 2009) or electronic accesses of a particular paper (Kurtz et al., 2005). Usage statistics are able to capture broader research activities (Kurtz \& Bollen, 2010) and are obtainable earlier (Brody, Harnad, \& Carr, 2006) than citation indicators. As a result, several metrics based on article download data have been suggested for measuring the impact of scientific publications (Bollen, Van De Sompel, Hagberg, \& Chute, 2009). However, most investigations have employed local usage data since global usage statistics are hidden by commercial publishers (Schloegl \& Gorraiz, 2010) because of privacy and marketing issues. The value of a download also depends on who accessed an article and how it was used (Thelwall, 2012). Moreover, the availability of an article through multiple platforms (Rowlands \& Nicholas, 2007) and "data aggregation" are other challenges for accurate usage data (Haustein \& Siebenlist, 2011).

The altmetrics movement has formed with the aim of capturing new and previously invisible impacts of scholarly publications based on crowdsourcing data in social web platforms like blogs, microblogs, social bookmarking tools and online reference managers (Priem, Taraborelli, Groth, \& Neylon, 2011). Data collection for altmetrics can often be based on open Applications Programming Interfaces (APIs) (Priem, Piwowar, \& Hemminger, 2012) which are faster and more accessible than classical usage data and are easy to integrate (Priem et al., 2011). Amongst web 2.0 platforms, social bookmarking tools, such as CiteULike, Connotea and BibSonomy, may help to overcome the lack of global and "publisherindependent" usage data (Haustein \& Siebenlist, 2011). A particularly promising example is Mendeley, a reference manager website that claims to have 2 million users and a database 45 times larger than its competitor CiteULike. Mendeley is a free global and collaborative commercial online reference manager tool launched in 2009. Online reference manager tools are web-based platforms for academics and students to record, manage and share their personal bibliographies. Although there has been much discussion about the value of Mendeley as an altmetrics source (Priem \& Hemminger, 2010; Bar-Ilan et al., 2012; Bar-Ilan, 2012), it has not yet been fully evaluated. Previous investigations have found a correlation 
between Mendeley readership and citation counts for Nature and Science articles ( $\mathrm{Li}$, Thelwall, \& Giustini, 2012) and for Genomics and Genetics papers (Li \& Thelwall, 2012) but no study so far has examined the relationship between the two measures across different disciplines. The present research addresses this issue by assessing whether the relationship between Mendeley readership and citation counts varies across different social sciences and humanities disciplines. Social sciences and humanities studies are not cumulative and topics are not globally agreed in these disciplines (Becher \& Trowler, 2001); thus citation analysis has more limitations for measuring the research performance of these areas than for the hard sciences (Nederhof, 2006). As a result, developing appropriate indicators for the research evaluation of the social sciences and humanities has been important for the last three decades (Moed, Linmans, \& Nederhof, 2009). Additionally, "usage metrics" are reasonable measures for fields within the social sciences and humanities with many pure readers (Armbruster, 2008).

Another task that altmetrics may aid is assessing how knowledge travels across disciplinary boundaries, or "information flow". Cross-disciplinary citations are routinely used to measure the information flow from one discipline to another, but this is not ideal (Rinia, Van Leeuwen, Bruins, Van Vuren, \& Van Raan, 2002) due to the inherent limitations of citation analysis. For instance, using only citation data to capture information flow across scientific areas will lead an incomplete analysis as it is based only on publication data while there are many valid reasons for using scientific papers that will not lead to citing them. Moreover, citation delays are a common limitation for tracking information flows across different disciplines (Rinia, Van Leeuwen, Bruins, Van Vuren, \& Van Raan, 2001). Thus, another objective of this study is to examine whether Mendeley can be applied to measure an aspect of information flow between scientific disciplines.

\section{Related Research}

\section{Bookmarking and Mendeley}

Social web services can connect both people (Ding et al., 2009) and documents. Scholars can now communicate via web 2.0 products, including social bookmarking sites, Twitter, blogs, and wikis. These tools are potential sources of data for measuring the impact of scholarly publications at the article and journal levels, although many properties of these social platforms are not revealed by their owners (Eysenbach, 2011).

Online reference managers and social bookmarking sites are personal information management tools that some researchers use in their daily activities. User interactions in social bookmarking sites can provide valuable data that could be useful for research evaluation (Neylon \& Wu, 2009). For example, there seems to be plentiful data about biomedicine articles in social bookmarking platforms (Priem et al., 2012). A case study of BibSonomy revealed that the most bookmarked publication types were journal articles (Borrego \& Fry, 2012). Haustein and Siebenlist (2011) used bookmarking data for 45 physics journals from CiteULike, Connotea and BibSonomy in order to evaluate the journals.

There is evidence that at least some altmetrics can correlate with citations, supporting the hypothesis that they can be valuable indicators of an aspect of research impact. Significant correlations between several indicators derived from social bookmarking data and JIFs (Journal Impact Factors) indicate that social bookmarking data could be useful for evaluating journal utility from the reader's perspective. Comparing Mendeley and CiteULike user counts with WoS (Web of Science) and Google scholar (GS) citation counts for 1613 Nature and Science articles from 2007, Li, Thelwall and Giustini (2012) found significant correlations between the bookmarking data and citation counts and concluded that Mendeley was more appropriate than CiteULike for research assessment in the studied sample. Bar-Ilan (2012) compared WoS, GS and Scopus citation counts for the Journal of the American Society for 
Information Science and Technology between 2001 and 2010 with Mendeley readership counts. Moderate correlations of around 0.5 suggested that "reading and citing are two different scientific activities". Li and Thelwall (2012) examined the relationship between citations and two altmetric indicators: Mendeley readership counts and F1000 article factors (a post-publication peer review score) for a sample of Genomics and Genetics articles published in 2008 that were reviewed by F1000 Faculty Members. They found significant correlations between citation counts and the two altmetric measures. The correlations were stronger for Mendeley readership counts than for FFa scores, further evidence of the potential value of bookmarking data.

\section{Interdisciplinary Knowledge transfer}

Science policymakers and funders sometimes promote interdisciplinary research to overcome sophisticated research problems (Levitt \& Thelwall, 2011) and cross-fertilization seems also to be a vital element in modern science (Morillo, Bordons, \& Gómez, 2003). Thus, researchers may use publications from outside their disciplines more (Bordons, Morillo, \& Gómez, 2005). Based on information flow between disciplines, interdisciplinarity can be conceptualized in two different ways: big and small (Rinia, 2007). Small interdisciplinarity deals with interactions between sub-disciplines while big interdisciplinarity refers to relations between different disciplines. It seems that some disciplines are mainly "donors" while others are "receptors" (Pair,1980). In other words, researchers from some disciplines provide food for thought for other disciplines while several disciplines are mainly importers of ideas from others. It is therefore increasingly important to study the information flow between disciplines to uncover the contributions of scientific disciplines from different points of view.

A number of previous studies have attempted to measure interdisciplinarity in the social sciences and humanities mainly based on citation analysis. Urata (1990) used citation flows and expert migration to identify relationships between social sciences and humanities disciplines in Japan. The results revealed that sociology and education imported many ideas from other disciplines while psychology, linguistics, philosophy and history exported though to other areas. For the social sciences, Gingras and Larivière (2010) found that interdisciplinary decreased from 1965 to 1992, but rose sharply after 1994. Levitt and Thelwall (2011) investigated changes of interdisciplinarity in social sciences disciplines in 1990 and 2000 with similar results: interdisciplinarity diminished between 1980 and 1990 but increased strongly from 1990 to 2000. Stevens (1990) examined the relationship between planning and other social sciences disciplines. He found that half of the planning information came from economics while geography, environmental studies and economics were the main users of planning publications. An investigation into articles from four major sociology and political science journals indicated that the boundaries of these disciplines were not limited (Pierce, 1999). Goldstone and Leydesdorff (2006) claimed that cognitive science, as an interdisciplinary subject, is a hub for knowledge exchange between computer science, neuroscience, psychology and education. Cognitive science articles were often used by computer scientists while cognitive science researchers cited psychology publications more. Neeley (1981) applied citation analysis to measure the relationship of management to other social science fields, finding that management scholars often cited other disciplines but not vice versa. Another study of management journals revealed that this field was a significant donor for psychology while a large amount of information was imported from economics, psychology, and sociology (Lockett \& McWilliams, 2005).

Cronin and Pearson (1990) analysed citations to the scholarly artefacts of some senior information scientists and found that few of these publications were used by scholars from outside the field. Conversely, results of an empirical study in 2005 showed that the pattern of 
LIS (Library and Information Science) research had changed in terms of interdisciplinarity and LIS articles had been cited by several other disciplines (Tang, 2005). Cronin and Meho (2007) used large-scale data to re-examine the conclusions of Cronin and Pearson (1990), finding that information science had transferred ideas to other disciplines more and used publications from computer science, engineering, and business and management more in the last decade. More recently, LIS has had the highest increase in interdisciplinarity among the other social sciences disciplines (Levitt \& Thelwall, 2011).

Social bookmarking and reference data have also been used for discovering relations between disciplines. Jiang, He, and Ni (2011) clustered journals and authors from occurrences and co-occurrences in CiteULike and compared the results with clusters generated from crosscitations and co-citations from WoS. The results indicated that although CiteULike data was able to show relationships between publications, it is not as good as citation-based data for showing connections in the literature because of the sparseness of data in CiteULike. Kraker, Körner, Jack, and Granitzer (2012) used "co-readership" of saved articles in Mendeley users' profiles to discover new emerging areas in the technology-enhanced learning field. An analysis of 1,025 personal libraries in Mendeley revealed that it was possible to uncover new emerging topics based on usage data. Although the investigated sample was limited to a small subject, they concluded that Mendeley could be useful for real time and accurate knowledge domain visualization.

In summary, measuring information flows based on citation analysis is an established method for discovering disciplines' influences on each other. Nevertheless, it is restricted to citation data and hence the behaviour of authors so it may not fully represent a complete picture of knowledge transfers among scientific disciplines. Although some studies have shown that social bookmarking data could be valuable for measuring connections between disciplines, they were restricted to CiteUlike with smaller database in comparison with Mendeley (Jiang, He, \& Ni, 2011) or were limited to a particular research area (Kraker, Körner, Jack, \& Granitzer, 2012). Additionally, characteristics of scientific disciplines in terms on information flow based on social bookmarking data have not been addressed clearly in previous research. Thus, a systematic study for discovering information flows based on social bookmarking data particularly for social sciences and humanities with many readers are needed.

\section{Research questions}

Although previous studies have found significant medium correlations between citations and Mendeley readership counts for specific sets of articles, it seems that no previous research has investigated the relationship between Mendeley readership counts and citation measures across a range of disciplines. This is an important omission because the citation behaviours of disciplines are known to vary and so Mendeley readership counts may not always correlate with citation counts. The current research partly fills this gap by investigating the correlation between Mendeley readership and citation counts for different social sciences and humanities disciplines. We also use Mendeley readership data to discover relationships between social sciences and humanities disciplines (i.e., on a much larger scale than previously attempted with Mendeley), assessing whether the results are reasonable through comparisons with crossdisciplinary citations. The following research questions drive the investigation.

1. Are there significant, substantial and positive correlations between Mendeley readership counts and citation measures in all social sciences and humanities disciplines? If so, are there significant differences between disciplines?

2. To what extent do Mendeley bookmark data reflect similar information flow patterns as the cross-disciplinary citations in WoS? 


\section{Data collection}

For data collection, we used the advance search options of WoS online to retrieve all social sciences and humanities articles indexed by WoS in the year 2008. The results were limited to research articles in English (removing reports, editorials, book reviews, etc.). The year 2008 was selected because the peak time for citations is usually three years after an article is released (Moed, 2005). In order to classify the retrieved records to social sciences and humanities disciplines, we used the "Analyze Results" and then refining the documents to the "Research Areas" which is abbreviated "SU" at the WoS interface ${ }^{2}$. Finally, ten social sciences and humanities disciplines were selected for this study to give a wide range, as shown in Table 1. In other words, scientific disciplines were operationalized based on WoS Research Areas in this research. The level of aggregation for WoS Research Areas is higher than for WoS categories (Leydesdorff, Carley, \& Rafols, 2013). For instance, all subdisciplines of psychology are classified as a single discipline named psychology. In the next step, bibliographic information and citation counts for all publications in the selected disciplines were downloaded from WoS for further analysis.

Mendeley users save reference information in their libraries. In the current research, the number of Mendeley users that had saved a paper is considered to be its Mendeley readership count. In order to get the Mendeley readership data, we used Webometric Analyst (lexiurl.wlv.ac.uk) to automatically extract Mendeley readership counts for the downloaded articles from WoS via the Mendeley API. As multiple versions of an article sometimes exist in Mendeley, we identified duplicate records based on Mendeley unique IDs, Mendeley URLs, and DOIs. Probable duplications were manually checked and removed. Out of 41,624 Mendeley records, 1,166 records (3\%) were judged to be duplicates. Some of the articles in the Mendeley catalogue did not have readership statistics and instead of statistical data the phrase "Readership statistics are being calculated" was displayed. It appears that Mendeley loaded these articles straight from the publishers' websites or some users had added their own publications to their Mendeley profiles but no one had saved these articles into a personal library. Most of the records removed due to duplication did not have readership statistics.

Table 1 shows that an average of $44 \%$ of the article from the chosen social sciences was in the Mendeley catalogue in comparison to only $13 \%$ of the humanities articles. Psychology (54\%) and linguistics (34\%) had the highest coverage in Mendeley within the social sciences and humanities respectively. Education (39\%) and Literature (4\%) had the lowest percentages of articles in the Mendeley database. In total, 27,558 social science articles and 1,914 humanities articles with Mendeley readership statistics were used. Spearman correlation tests were applied to the WoS citations and Mendeley readership counts. Spearman correlation was used rather than Pearson correlation because the frequency distributions of readership and citation counts were skewed.

In the current article, we used citations and Mendeley readership counts publications as two approaches for measuring information flow across different disciplines. For this purpose, the same search methods for retrieving the data from SSCI and AHCI were used and using "create citation report", we extracted citing disciplines based on WoS Research Area for the ten social science and humanities disciplines. For computing the information flow based on Mendeley readership, users' research backgrounds in Mendeley profiles were used. Data

\footnotetext{
${ }^{2}$ http://images.webofknowledge.com/WOKRS510B3_1/help/WOS/hp_research_areas_easca.html
} 
are accessible through the Mendeley API for only the three most common readers' background disciplines for each individual article. The data is provided as percentages rather than total numbers of readers. For each article and each of the three readers' disciplines returned, we multiplied the percentage of readers from the discipline with the total number of readers of the article and divided by 100 to obtain the estimated number of article readers from that discipline. This process covered $89 \%$ and $82 \%$ of the readers' background disciplines for social science and humanities articles.

Table1. Coverage of WoS articles from social sciences and humanities disciplines in Mendeley.

\begin{tabular}{|c|c|c|c|c|}
\hline WoS discipline & $\begin{array}{l}\text { Articles } \\
\text { indexed by } \\
\text { WoS in } 2008\end{array}$ & $\begin{array}{l}\text { WoS articles } \\
\text { covered by } \\
\text { Mendeley }\end{array}$ & $\begin{array}{l}\text { Articles with } \\
\text { readership } \\
\text { statistics }\end{array}$ & $\begin{array}{l}\text { Articles without } \\
\text { readership } \\
\text { statistics }\end{array}$ \\
\hline Psychology & 23,811 & $14,757(62 \%)$ & $12,804(54 \%)$ & $1,953(8 \%)$ \\
\hline $\begin{array}{l}\text { Social Sciences Other } \\
\text { Subjects }\end{array}$ & 6,366 & $3,763(59 \%)$ & $2,416(38 \%)$ & $1,347(21 \%)$ \\
\hline $\begin{array}{l}\text { Education \& } \\
\text { Educational Research }\end{array}$ & 7,208 & $3,839(53 \%)$ & $2,796(39 \%)$ & $1,043(14 \%)$ \\
\hline $\begin{array}{l}\text { Information Science } \\
\text { \& Library Science }\end{array}$ & 2,552 & $1,617(63 \%)$ & $1,343(53 \%)$ & $274(10 \%)$ \\
\hline $\begin{array}{l}\text { Business \& } \\
\text { Economics }\end{array}$ & 22,710 & $12,337(54 \%)$ & $8,199(36 \%)$ & $4,138(18 \%)$ \\
\hline Social sciences total & 62,647 & $36,313(58 \%)$ & $27,558(44 \%)$ & $8,755(14 \%)$ \\
\hline Philosophy & 2,833 & $1,060(37 \%)$ & $468(17 \%)$ & $592(21 \%)$ \\
\hline History & 2,882 & $756(26 \%)$ & $253(9 \%)$ & $503(17 \%)$ \\
\hline Linguistics & 2,245 & $1,046(47 \%)$ & $773(34 \%)$ & $273(12 \%)$ \\
\hline Literature & 4,622 & $643(14 \%)$ & $165(4 \%)$ & $478(10 \%)$ \\
\hline Religion & 2,058 & $640(31 \%)$ & $255(12 \%)$ & $385(19 \%)$ \\
\hline Humanities total & 14,640 & $4,145(28 \%)$ & $1,914(13 \%)$ & $2,231(15 \%)$ \\
\hline
\end{tabular}

\section{Results}

The data was analysed separately for the two research questions.

\section{Correlations between WoS citations and counts of Mendeley readers}

Table 2 shows that there is a significant correlation between Mendeley readership and citation counts in all the investigated disciplines. The correlation for social sciences disciplines overall $(\mathrm{r}=0.516, \mathrm{p}<.01)$ is higher than that for humanities disciplines $(\mathrm{r}=0.428, \mathrm{p}<.01)$. In order to measure the substantial correlations we considered $\mathrm{r}=0.1+, 0.3+0.5+$ as small, medium, and large correlations, respectively (Cohen, 1988), and we consider medium and large correlations to be substantial in the sense of the research question. There correlations for social sciences disciplines were medium, varying from $\mathrm{r}=0.403, \mathrm{p}<.01$ (Social Sciences Other Subjects) to $\mathrm{r}=0.573, \mathrm{p}<.01$ (Business and Economics). Amongst humanities disciplines, Religion and Philosophy have the lowest correlations $(r=0.363, p<.01$ and $r=0.366, p<.01)$ and Linguistics has the highest correlation $(\mathrm{r}=0.454, \mathrm{p}<.01)$.

Table 2. Correlations between WoS citations and Mendely readership counts (non-zero only) for 2008 articles. 


\begin{tabular}{|l|l|l|l|}
\hline Selected WoS discipline & $\begin{array}{l}\text { WoS citation } \\
\text { median }\end{array}$ & $\begin{array}{l}\text { Mendeley } \\
\text { readership } \\
\text { median }\end{array}$ & $\begin{array}{l}\text { Correlation } \\
\text { between Mendeley } \\
\text { readership and } \\
\text { citation counts }\end{array}$ \\
\hline Psychology & 6 & 6 & $.514^{* *}$ \\
\hline $\begin{array}{l}\text { Social Sciences Other } \\
\text { Subjects }\end{array}$ & 4 & 4 & $.403^{* *}$ \\
\hline $\begin{array}{l}\text { Education \& Educational } \\
\text { Research }\end{array}$ & 4 & 6 & $.484^{* *}$ \\
\hline $\begin{array}{l}\text { Information Science \& Library } \\
\text { Science }\end{array}$ & 4 & 8 & $.535^{* *}$ \\
\hline Business\& Economics & 5 & 7 & $.573^{* *}$ \\
\hline All selected social sciences & 5 & 6 & $.516^{* *}$ \\
\hline Philosophy & 1 & 4 & $.366^{* *}$ \\
\hline History & 1 & 2 & $.428^{* *}$ \\
\hline Linguistics & 2 & 4 & $.454^{* *}$ \\
\hline Literature & 0 & 2 & $.403^{* *}$ \\
\hline Religion & 1 & 3 & $.363^{* *}$ \\
\hline All selected humanities & $\mathbf{1}$ & $\mathbf{3}$ & $.428^{* *}$ \\
\hline
\end{tabular}

$* *$ Significant at the $\mathrm{p}=0.01$ level

The Table 2 results might be misleading if articles that were not in Mendeley tended to be substantially cited and so we repeated the analysis but included articles not covered by Mendeley. In this new analysis, the readership counts of those articles that were not included in Mendeley were set at zero. As shown in Table 3, the second correlations between Mendeley readership counts and the number of citations are weaker for both social sciences $(\mathrm{r}=0.350, \mathrm{p}<.01)$ and humanities $(\mathrm{r}=0.280, \mathrm{p}<.01)$ disciplines overall in comparison to the Table 2 correlations. IS\&LS $(r=0.369, \mathrm{p}<.01)$ and Linguistics $(r=0.162, p<.01)$ had the highest correlations while Social Sciences Other Subjects $(r=0.293, p<.01)$ and Literature $(\mathrm{r}=0.162, \mathrm{p}<.01)$ had the lowest correlations among social sciences and humanities disciplines respectively. The median citations of articles with zero Mendeley bookmarks for all social sciences disciplines is 2 while the median for the other Mendeley article of all the disciplines is 5. For humanities disciplines, the median number of citations to articles with no Mendeley readers is 0 while the median for articles with readership counts in Mendeley is 1 . The small difference between these two medians may be the reason for the decreased correlations between citations and Mendeley bookmarks in the second analysis.

Table 3. Spearman correlations between citations and Mendeley readership counts for all WoS articles from 2008 in different social sciences and humanities disciplines.

\begin{tabular}{|l|l|l|l|}
\hline Selected WoS discipline & $\begin{array}{l}\text { WoS citation } \\
\text { median }\end{array}$ & $\begin{array}{l}\text { Mendeley } \\
\text { readership } \\
\text { median }\end{array}$ & $\begin{array}{l}\text { Correlation } \\
\text { between } \\
\text { Mendeley } \\
\text { readership and } \\
\text { citation counts }\end{array}$ \\
\hline Psychology & 5 & 1 & $.311^{* *}$ \\
\hline Social Sciences Other Subjects & 2 & 0 & $.293^{* *}$ \\
\hline Education \& Educational Research & 2 & 0 & $.308^{* *}$ \\
\hline
\end{tabular}




\begin{tabular}{|l|l|l|l|}
\hline Library and Information Science & 2 & 1 & $.369^{* *}$ \\
\hline Business \& Economics & 3 & 0 & $.359^{* *}$ \\
\hline All selected social sciences & 3 & 0 & $.350^{* *}$ \\
\hline Philosophy & 0 & 0 & $.215^{* *}$ \\
\hline History & 0 & 0 & $.193^{* *}$ \\
\hline Linguistics & 1 & 0 & $.312^{* *}$ \\
\hline Literature & 0 & 0 & $.162^{* *}$ \\
\hline Religion & 0 & 0 & $.222^{* *}$ \\
\hline All selected humanities & $\mathbf{0}$ & $\mathbf{0}$ & $.280^{* *}$ \\
\hline
\end{tabular}

** Significant at the $\mathrm{p}=0.01$ level

\section{Knowledge flows based upon Mendeley readers}

The remaining tables address the second research question and compare the disciplines of articles with those of their readers. The WoS subject categories do not match the Mendeley categories $^{3}$ and so the comparisons are all approximate. To aid the analysis, similar Mendeley categories were merged in to broader categories and categories with low readership percentages were merged into a single 'Others' category. Detailed information about the merged Mendeley categories is provided in Appendices 1 and 2. For citing disciplines, as shown in Tables 5 and 7, small citing research areas have been merged into the main disciplines(detail information can be seen in Appendices 3 and 4). For example, all sub-fields of medicine were merged in to a broader Medicine and Health category. From Table 4, the majority of readers of all five selected WoS social science disciplines are from the home disciplines, except for IS\&LS and the broad Social Sciences Other Subjects category. However, the percentages vary across different disciplines, from Psychology (64\%) to Social Sciences Other Subjects (28\%). This suggests that most Mendeley readers use scientific information mainly from their own disciplines but this varies substantially between disciplines. The research backgrounds of many readers of IS\&LS articles (46\%) are computer and information scientists who might possibly be more commonly computer scientists rather than library scientists.

Very few Psychology articles have an Arts and Humanities readership while some Psychology literature is read by people from Biology (7\%) and Medicine (6\%), perhaps reflecting crossover fields like neuropsychology and psychopharmacology.

Table 4. Mendeley readership categories for year 2008 articles from the five selected social sciences. Home categories are in bold for each WoS discipline; values above $10 \%$ are shaded.

\begin{tabular}{|c|c|c|c|c|c|c|}
\hline & \multicolumn{5}{|c|}{ Selected WoS discipline } \\
\hline & & Psychology & $\begin{array}{l}\text { Social } \\
\text { Sciences Other } \\
\text { Subjects }\end{array}$ & $\begin{array}{l}\text { Education } \\
\& \\
\text { Educational } \\
\text { Research }\end{array}$ & $I S \& L S$ & $\begin{array}{l}\text { Business \& } \\
\text { Economics }\end{array}$ \\
\hline \multirow{6}{*}{ 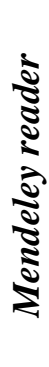 } & Psychology & $64.0 \%$ & $15.8 \%$ & $12.4 \%$ & $1.8 \%$ & $6.5 \%$ \\
\hline & Social Sciences & $6.5 \%$ & $27.8 \%$ & $7.4 \%$ & $20.5 \%$ & $11.6 \%$ \\
\hline & Education & $3.8 \%$ & $5.4 \%$ & $54.4 \%$ & $4.4 \%$ & $1.0 \%$ \\
\hline & $\begin{array}{l}\text { Computer and } \\
\text { Information Science }\end{array}$ & $3.1 \%$ & $4.5 \%$ & $9.0 \%$ & $45.9 \%$ & $4.7 \%$ \\
\hline & $\begin{array}{l}\text { Business \& } \\
\text { Economics }\end{array}$ & $3.5 \%$ & $11.6 \%$ & $1.9 \%$ & $14.0 \%$ & $55.7 \%$ \\
\hline & Management & $0.9 \%$ & $3.1 \%$ & $0.5 \%$ & $3.5 \%$ & $11.0 \%$ \\
\hline
\end{tabular}

\footnotetext{
${ }^{3}$ http://www.mendeley.com/directory/
} 


\begin{tabular}{|l|l|l|l|l|l|l|}
\hline & Medicine & $6.1 \%$ & $7.7 \%$ & $4.9 \%$ & $3.1 \%$ & $1.0 \%$ \\
\cline { 2 - 6 } & Biological Sciences & $6.6 \%$ & $4.5 \%$ & $1.7 \%$ & $1.4 \%$ & $1.5 \%$ \\
\cline { 2 - 6 } & Philosophy & $0.4 \%$ & $4.5 \%$ & $0.2 \%$ & $0.1 \%$ & $0.1 \%$ \\
\cline { 2 - 6 } & Linguistics & $1.9 \%$ & $0.1 \%$ & $3.0 \%$ & $0.2 \%$ & $0.0 \%$ \\
\hline Art and humanities & $0.5 \%$ & $2.7 \%$ & $1.0 \%$ & $1.4 \%$ & $0.2 \%$ \\
\cline { 2 - 6 } & Others & $2.6 \%$ & $12.3 \%$ & $3.4 \%$ & $3.6 \%$ & $6.6 \%$ \\
\hline & Total & 112898 & 13436 & 20817 & 13000 & 74080 \\
\hline
\end{tabular}

Table 5 indicates the disciplines that cited social sciences articles published in 2008. For most of the disciplines, the majority of papers were cited by publications of the home disciplines, except for IS\&LS. The percentage of IS\&LS papers cited by IS\&LS publications is $24 \%$ which is less than the percentage of Computer Science documents $(25 \%)$ that cited IS\&LS papers.

Table 5. Disciplines citing articles social sciences articles published in 2008. Home disciplines are are in bold for each WoS discipline; values above $10 \%$ are shaded.

\begin{tabular}{|c|c|c|c|c|c|c|}
\hline & \multicolumn{5}{|c|}{ Selected WoS discipline } \\
\hline & & Psychology & $\begin{array}{l}\text { Social Sciences } \\
\text { Other Subjects }\end{array}$ & $\begin{array}{l}\text { Education \& } \\
\text { Educational } \\
\text { Research }\end{array}$ & $I S \& L S$ & $\begin{array}{l}\text { Business \& } \\
\text { Economics }\end{array}$ \\
\hline & Psychology & $33.4 \%$ & $8.7 \%$ & $12.5 \%$ & $2.6 \%$ & $4.3 \%$ \\
\hline & Social Sciences & $7.7 \%$ & $32.0 \%$ & $7.5 \%$ & $6.0 \%$ & $11.7 \%$ \\
\hline & Education & $2.9 \%$ & $2.3 \%$ & $36.2 \%$ & $2.5 \%$ & $0.8 \%$ \\
\hline & IS\&LS & $0.2 \%$ & $0.6 \%$ & $0.8 \%$ & $24.0 \%$ & $1.3 \%$ \\
\hline & $\begin{array}{l}\text { Business \& } \\
\text { Economics }\end{array}$ & $2.8 \%$ & $8.6 \%$ & $2.1 \%$ & $9.9 \%$ & $43.1 \%$ \\
\hline & Management & $0.2 \%$ & $1.6 \%$ & $0.5 \%$ & $3.0 \%$ & $7.0 \%$ \\
\hline & $\begin{array}{l}\text { Medicine and } \\
\text { Health }\end{array}$ & $39.1 \%$ & $25.6 \%$ & $24.9 \%$ & $11.7 \%$ & $5.8 \%$ \\
\hline$\approx$ & $\begin{array}{l}\text { Biology and Life } \\
\text { Sciences }\end{array}$ & $7.0 \%$ & $5.5 \%$ & $2.7 \%$ & $2.8 \%$ & $5.8 \%$ \\
\hline .5 & $\begin{array}{l}\text { Computer } \\
\text { Science }\end{array}$ & $1.1 \%$ & $1.6 \%$ & $4.5 \%$ & $25.0 \%$ & $3.9 \%$ \\
\hline$\cong$ & Engineering & $0.9 \%$ & $3.1 \%$ & $2.0 \%$ & $4.9 \%$ & $4.7 \%$ \\
\hline 5 & Linguistics & $1.2 \%$ & $0.2 \%$ & $2.7 \%$ & $0.1 \%$ & $0.0 \%$ \\
\hline $\begin{array}{l}3 \\
30 \\
30\end{array}$ & $\begin{array}{l}\text { Art and } \\
\text { Humanities }\end{array}$ & $0.6 \%$ & $3.8 \%$ & $1.1 \%$ & $0.6 \%$ & $0.5 \%$ \\
\hline ن & Others & $2.7 \%$ & $6.2 \%$ & $2.5 \%$ & $6.8 \%$ & $11.0 \%$ \\
\hline & Total & 272957 & 39926 & 36520 & 16751 & 167996 \\
\hline
\end{tabular}

Table 6 shows that the main users of Philosophy (32\%) and Linguistics (55\%) publications are from the same discipline. The situation of Literature is unusual because $27 \%$ of readers are in the broad Arts and Literature category but $28 \%$ are in the Humanities category that is also relevant to literature. In contrast, the main users of History (40\%) and Religion articles 
(27\%) are from Social Sciences rather than their home disciplines (which are within Humanities in both cases).

Table 6. Mendeley readership categories for year 2008 articles from the five chosen Humanities disciplines. Home categories are highlighted for each WoS discipline.

\begin{tabular}{|c|c|c|c|c|c|c|}
\hline & \multicolumn{5}{|c|}{ Selected WoS discipline } \\
\hline & & Philosophy & History* & Linguistics & Literature & Religion* \\
\hline \multirow{12}{*}{ 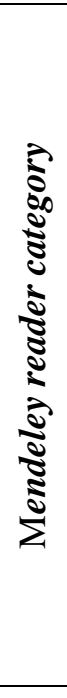 } & Philosophy & $32.1 \%$ & $4.0 \%$ & $1.2 \%$ & $0.9 \%$ & $6.6 \%$ \\
\hline & Humanities & $7.2 \%$ & $31.7 \%$ & $4.7 \%$ & $27.8 \%$ & $23.1 \%$ \\
\hline & Linguistics & $2.6 \%$ & $0.7 \%$ & $\mathbf{5 5 . 0 \%}$ & $1.2 \%$ & $2.5 \%$ \\
\hline & Arts and Literature & $2.6 \%$ & $3.8 \%$ & $2.5 \%$ & $27.3 \%$ & $1.7 \%$ \\
\hline & Social Sciences & $12.4 \%$ & $39.6 \%$ & $7.8 \%$ & $20.6 \%$ & $26.9 \%$ \\
\hline & Psychology & $15.6 \%$ & $6.5 \%$ & $8.4 \%$ & $1.3 \%$ & $21.4 \%$ \\
\hline & Education & $3.7 \%$ & $2.4 \%$ & $7.9 \%$ & $2.6 \%$ & $6.4 \%$ \\
\hline & Business \& Economics & $1.1 \%$ & $1.2 \%$ & $0.1 \%$ & $1.0 \%$ & $1.1 \%$ \\
\hline & Medicine & $2.4 \%$ & $0.7 \%$ & $0.5 \%$ & $1.0 \%$ & $3.4 \%$ \\
\hline & Biological Sciences & $5.0 \%$ & $0.7 \%$ & $0.9 \%$ & $0.6 \%$ & $2.3 \%$ \\
\hline & $\begin{array}{l}\text { Computer and } \\
\text { Information Science }\end{array}$ & $6.5 \%$ & $2.8 \%$ & $9.3 \%$ & $10.1 \%$ & $1.1 \%$ \\
\hline & Others & $8.8 \%$ & $5.9 \%$ & $1.7 \%$ & $5.6 \%$ & $3.5 \%$ \\
\hline & Total & 1153 & 911 & 3760 & 650 & 812 \\
\hline
\end{tabular}

*History and Religion are sub-categories of the Mendeley Humanities category (http://www.mendeley.com/disciplines/humanities/).

From Table 7, most disciplines citing humanities articles are also the home disciplines except in the case of History. However, more than half of the disciplines citing humanities publications are other disciplines. Comparing information flows based on citing and Mendeley bookmarking for humanities disciplines shows that they are similar in most cases. Nevertheless, there are some differences in terms of the strengths of connections between the disciplines. For instance, Mendeley usage data gives stronger connections between History, Psychology and Computer Science while citation data gives stronger relationships between History, Medicine and Biology.

Table 7. Disciplines citing humanities articles published in 2008. Home disciplines are highlighted for each WoS discipline.

\begin{tabular}{|c|c|c|c|c|c|c|}
\hline & \multicolumn{5}{|c|}{ Selected WoS discipline } \\
\hline & & Philosophy & History & Linguistics & Literature & Religion \\
\hline \multirow{7}{*}{ 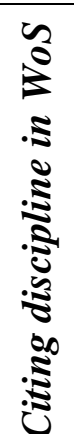 } & Philosophy & $46.4 \%$ & $3.1 \%$ & $1.1 \%$ & $2.7 \%$ & $4.00 \%$ \\
\hline & History & $0.9 \%$ & $35.0 \%$ & $0.5 \%$ & $3.6 \%$ & $4.3 \%$ \\
\hline & Linguistics & $2.3 \%$ & $0.6 \%$ & $48.3 \%$ & $8.3 \%$ & $0.2 \%$ \\
\hline & Literature & $1.1 \%$ & $2.0 \%$ & $3.0 \%$ & $44.5 \%$ & $1.0 \%$ \\
\hline & Religion & $1.6 \%$ & $2.5 \%$ & $0.1 \%$ & $1.2 \%$ & $39.0 \%$ \\
\hline & $\begin{array}{l}\text { Arts \& Humanities } \\
\text { Other Subjects }\end{array}$ & $1.1 \%$ & $4.7 \%$ & $1.1 \%$ & $10.7 \%$ & $1.8 \%$ \\
\hline & Social Sciences & $17.6 \%$ & $34.5 \%$ & $9.8 \%$ & $17.5 \%$ & $23.9 \%$ \\
\hline
\end{tabular}




\begin{tabular}{|l|l|l|l|l|l|l|}
\hline Psychology & $6.2 \%$ & $1.2 \%$ & $11.0 \%$ & $1.6 \%$ & $8.7 \%$ \\
\cline { 2 - 6 } & Education & $1.7 \%$ & $0.9 \%$ & $7.6 \%$ & $2.8 \%$ & $4.2 \%$ \\
\hline Business Economics & $1.5 \%$ & $6.8 \%$ & $0.4 \%$ & $0.7 \%$ & $0.7 \%$ \\
\hline Medicine and Health & $4.0 \%$ & $1.9 \%$ & $6.2 \%$ & $1.0 \%$ & $7.0 \%$ \\
\hline $\begin{array}{l}\text { Biology and Life } \\
\text { Sciences }\end{array}$ & $3.4 \%$ & $2.4 \%$ & $1.9 \%$ & $1.2 \%$ & $1.7 \%$ \\
\hline Computer Science & $3.6 \%$ & $0.5 \%$ & $4.3 \%$ & $1.4 \%$ & $1.2 \%$ \\
\hline Others & $8.5 \%$ & $3.8 \%$ & $4.70 \%$ & $2.7 \%$ & $2.5 \%$ \\
\hline Total & 4222 & 2829 & 5282 & 1876 & 1822 \\
\hline
\end{tabular}

\section{Limitations}

One limitation of this research is that readership is limited to the individuals who choose Mendeley for their reference manager while many scholars use other similar tools, such as EndNote, RefWorks, and ProCite, to organize their references or do not use a reference manager. Another limitation is that around $11 \%-18 \%$ of the readers' background disciplines were excluded because they were not accessible via the Mendeley API and so the contribution of minor subjects and the extent of interdisciplinarity may be underrepresented. The results also reflect the size of the disciplines involved and the extent to which Mendeley is used within these disciplines. Hence, the results are likely to be skewed towards disciplines using Mendeley the most actively (e.g., perhaps IS\&LS).

The WoS research areas used to define disciplines and the overlap between WoS subjects are also a limitation for this research because $25 \%$ of WoS journals are classified in more than one subject (Rinia, Van Leeuwen, Bruins, Van Vuren, \& Van Raan, 2002). However, it is not easy to label research publications in a single subject particularly for multidisciplinary research areas and the disciplines with more common research boarders. Our classifications for citation flow is based on WoS research areas which is at a journal level while the categorization for cross readership is based on research interests of Mendeley users. As paper could appear in more than one WoS research area category but Mendeley users can chose only one research interest for a paper. Therefore, this issue can affect the information flows in terms of readership and citation. For example, a paper that has been classified in two disciplines in WoS but only one in Mendeley will appear to be part of an information flow between areas for at least one of the WoS disciplines.

Finally, our sample is restricted to journal articles only although books are a fundamental source of research in many humanities and some social science disciplines (Huang \& Chang, 2008; Nederhof, 2006). However, social sciences and humanities researchers have begun to publish more in WoS journals (Kyvik, 2003; Butler, 2003)

\section{Discussion}

This research examined Mendeley usage data for social sciences and humanities publications from 2008. In answer to the first research question, there were statistically significant medium positive correlations between Mendeley readership counts and citations for all the studied disciplines but the values varied across disciplines. The highest correlations between Mendeley readership counts and citations are in those disciplines that are closer to hard sciences in terms of citation behaviour while the correlations are lower in the disciplines which more resemble traditional humanities. The median Mendeley readership counts were higher than the median citations for the articles covered by Mendeley in all the studied disciplines except psychology. In almost all disciplines, the correlation is not strong enough to conclude that Mendeley readership and citation counts measure the same aspect of research 
impact. As hypothesised by previous authors, a likely explanation is that Mendeley captures broader scholarly activities from a variety of readers' perspectives in comparison with citation counts.

In answer to the second question, comparing the knowledge transfer results across the disciplines examined based on citation data with Mendeley bookmark data shows that both datasets have similar overall patterns for the investigated disciplines. Nevertheless, there were some differences in the strength of links between the scientific subjects. For instance, Mendeley bookmark data gives stronger interdisciplinary connections in the humanities and most of the social sciences. Thus, the results of this study support the value of using Mendeley readership data to discover meaningful knowledge transfer patterns across scientific disciplines. This confirmation is evidence that Mendeley is a reasonable tool to measure information flow across scientific disciplines. This finding is in agreement with previous studies (Jiang, He, and Ni, 2011; Kraker, Körner, Jack, and Granitzer, 2012) which showed that social bookmarks tools provide valuable data source for discovering relationships between disciplines but the current study examined broader scientific disciplines.

\section{Conclusions}

The evidence from this study suggests that readership data could be a useful supplementary measure to remedy some limitations of citation analysis across the social sciences and humanities. If Mendeley readership data is to be used for important evaluations, however, then steps would need to be taken to ensure that the results cannot be manipulated by those with a vested interest in a particular outcome. These findings add to similar findings for other disciplines and, taken together, these now suggest that Mendeley may be universally useful for research impact estimation throughout all areas of scholarship. Mendeley has the advantage that it covers broader types of users, such as undergraduate and postgraduate students plus practitioners, while citation data comes only from authors. Mendeley data also may appear earlier than citations because of the lack of publication delays. The findings of this research also indicate that Mendeley data will be particularly useful when short term information flows are needed or a wider perspective than just publishing authors is needed. Finally, the research did not investigate what Mendeley readership counts refer to and future qualitative studies are needed to investigate this.

\section{Acknowledgments}

This is an extended version of an article accepted for oral presentation at the 14th International Conference Society of Scientometrics and Informetrics Conference 2013, Vienna, Austria - 15th-19th July. 
Appendix 1: Complete list of all merged Mendeley categories for readers of social sciences articles.

\begin{tabular}{|c|c|c|}
\hline Merged category & $\begin{array}{l}\text { Original Mendeley } \\
\text { category }\end{array}$ & $\begin{array}{l}\text { Total } \\
\text { readership }\end{array}$ \\
\hline Psychology & Psychology & $35.04 \%$ \\
\hline \multirow[t]{3}{*}{ Social Sciences } & Sports and Recreation & $0.52 \%$ \\
\hline & Social Sciences & $10.22 \%$ \\
\hline & Law & $0.15 \%$ \\
\hline Education & Education & $7.60 \%$ \\
\hline \multirow[t]{2}{*}{ Business \& Economics } & Economics & $7.06 \%$ \\
\hline & Business Administration & $13.96 \%$ \\
\hline $\begin{array}{l}\text { Management Science and } \\
\text { Operations Research }\end{array}$ & $\begin{array}{l}\text { Management Science } \\
\text { Operations Research }\end{array}$ & $4.35 \%$ \\
\hline $\begin{array}{l}\text { Computer and Information } \\
\text { Science }\end{array}$ & $\begin{array}{l}\text { Computer and Information } \\
\text { Science }\end{array}$ & $6.65 \%$ \\
\hline Medicine & Medicine & $4.33 \%$ \\
\hline Biological Sciences & Biological Sciences & $4.18 \%$ \\
\hline Philosophy & Philosophy & $0.56 \%$ \\
\hline Linguistics & Linguistics & $1.26 \%$ \\
\hline \multirow{2}{*}{ Arts and humanities } & Arts and Literature & $0.24 \%$ \\
\hline & Humanities & $0.47 \%$ \\
\hline \multirow[t]{10}{*}{ Others } & Physics & $0.16 \%$ \\
\hline & Mathematics & $0.21 \%$ \\
\hline & Materials Science & $0.02 \%$ \\
\hline & Environmental Sciences & $1.02 \%$ \\
\hline & Engineering & $1.16 \%$ \\
\hline & $\begin{array}{l}\text { Electrical and Electronic } \\
\text { Engineering }\end{array}$ & $0.15 \%$ \\
\hline & Earth Sciences & $0.16 \%$ \\
\hline & Design & $0.28 \%$ \\
\hline & Chemistry & $0.10 \%$ \\
\hline & $\begin{array}{l}\text { Astronomy, Astrophysics } \\
\text { \& Space Science }\end{array}$ & $0.01 \%$ \\
\hline Total & & 234231 \\
\hline
\end{tabular}

Appendix 2: Complete list of all merged categories for readers of humanities articles.

\begin{tabular}{|l|l|l|}
\hline Merged category & Original Mendeley category & Total readership \\
\hline Philosophy & Philosophy & $7.08 \%$ \\
\hline Humanities & Humanities & $12.62 \%$ \\
\hline Linguistics & Linguistics & $29.30 \%$ \\
\hline \multirow{2}{*}{ Arts and Literature } & Design & $0.17 \%$ \\
\cline { 2 - 3 } & Arts and Literature & $4.87 \%$ \\
\hline
\end{tabular}




\begin{tabular}{|c|c|c|}
\hline \multirow{4}{*}{ Social Sciences } & Sports and Recreation & $0.05 \%$ \\
\hline & Social Sciences & $15.82 \%$ \\
\hline & $\begin{array}{l}\text { Management Science and } \\
\text { Operations Research }\end{array}$ & $0.37 \%$ \\
\hline & Law & $0.38 \%$ \\
\hline Psychology & Psychology & $10.17 \%$ \\
\hline Education & Education & $5.95 \%$ \\
\hline \multirow{2}{*}{$\begin{array}{l}\text { Business } \\
\text { Economics }\end{array}$} & Economics & $0.86 \%$ \\
\hline & Business Administration & $0.60 \%$ \\
\hline Medicine & Medicine & $1.26 \%$ \\
\hline Biological Sciences & Biological Sciences & $1.70 \%$ \\
\hline $\begin{array}{l}\text { Computer and } \\
\text { Information Science }\end{array}$ & $\begin{array}{l}\text { Computer and Information } \\
\text { Science }\end{array}$ & $7.24 \%$ \\
\hline \multirow{9}{*}{ Others } & Physics & $0.24 \%$ \\
\hline & Mathematics & $0.10 \%$ \\
\hline & Materials Science & $0.00 \%$ \\
\hline & Environmental Sciences & $0.48 \%$ \\
\hline & Engineering & $0.35 \%$ \\
\hline & $\begin{array}{l}\text { Electrical and Electronic } \\
\text { Engineering }\end{array}$ & $0.12 \%$ \\
\hline & Earth Sciences & $0.13 \%$ \\
\hline & Chemistry & $0.02 \%$ \\
\hline & $\begin{array}{l}\text { Astronomy, Astrophysics \& } \\
\text { Space Science }\end{array}$ & $0.01 \%$ \\
\hline \multicolumn{2}{|r|}{ T } & 7286 \\
\hline
\end{tabular}

\section{Appendix3: Complete list of all merged WoS subject categories for disciplines citing social sciences articles.}

\begin{tabular}{|c|c|}
\hline Merged Category & ISI Subject Category \\
\hline Psychology & Psychology \\
\hline \multirow[t]{14}{*}{ Social sciences } & Criminology Penology \\
\hline & Family Studies \\
\hline & Biomedical Social Sciences \\
\hline & Government Law \\
\hline & Sociology \\
\hline & Communication \\
\hline & Social Work \\
\hline & Women Studies \\
\hline & Social Issues \\
\hline & Anthropology \\
\hline & Information Science Library Science \\
\hline & Mathematical Methods In Social Sciences \\
\hline & International Relations \\
\hline & Ethnic Studies \\
\hline
\end{tabular}




\begin{tabular}{|c|c|}
\hline & Cultural Studies \\
\hline & Urban Studies \\
\hline & Area Studies \\
\hline Education educational research & Education Educational Research \\
\hline Business \& Economics & Business \& Economics \\
\hline Operations research management science & Operations Research Management Science \\
\hline & Public Administration \\
\hline Medicine and health & Psychiatry \\
\hline & Public Environmental Occupational Health \\
\hline & Rehabilitation \\
\hline & Pediatrics \\
\hline & Sport Sciences \\
\hline & Pharmacology Pharmacy \\
\hline & General Internal Medicine \\
\hline & Health Care Sciences Services \\
\hline & Radiology Nuclear Medicine Medical Imaging \\
\hline & Nutrition Dietetics \\
\hline & Substance Abuse \\
\hline & Nursing \\
\hline & Geriatrics Gerontology \\
\hline & Ophthalmology \\
\hline & Audiology Speech Language Pathology \\
\hline & Oncology \\
\hline & Endocrinology Metabolism \\
\hline & Obstetrics Gynecology \\
\hline & Research Experimental Medicine \\
\hline & Otorhinolaryngology \\
\hline & Urology Nephrology \\
\hline & Anesthesiology \\
\hline & Surgery \\
\hline & Cardiovascular System Cardiology \\
\hline & Respiratory System \\
\hline & Immunology \\
\hline & Infectious Diseases \\
\hline & Rheumatology \\
\hline & Orthopedics \\
\hline & Integrative Complementary Medicine \\
\hline & Veterinary Sciences \\
\hline & Hematology \\
\hline & Medical ethics \\
\hline & Dentistry Oral Surgery Medicine \\
\hline & Gastroenterology Hepatology \\
\hline & Toxicology \\
\hline & Dermatology \\
\hline & Demography \\
\hline
\end{tabular}




\begin{tabular}{|c|c|}
\hline & Allergy \\
\hline & Legal Medicine \\
\hline & Tropical medicine \\
\hline & Emergency medicine \\
\hline & Medical laboratory technology \\
\hline Biology and life sciences & Physiology \\
\hline & Life Sciences Biomedicine Other Topics \\
\hline & Genetics Heredity \\
\hline & Environmental Sciences Ecology \\
\hline & Zoology \\
\hline & Biochemistry Molecular Biology \\
\hline & Evolutionary Biology \\
\hline & Cell Biology \\
\hline & Biophysics \\
\hline & Developmental Biology \\
\hline & Reproductive Biology \\
\hline & Anatomy Morphology \\
\hline & Biotechnology Applied Microbiology \\
\hline & Pathology \\
\hline & Virology \\
\hline & Plant sciences \\
\hline & Biodiversity Conservation \\
\hline & Marine Freshwater Biology \\
\hline & Microbiology \\
\hline & Parasitology \\
\hline Computer science & Computer Science \\
\hline Engineering & Engineering \\
\hline Linguistics & Linguistics \\
\hline Art and humanities & Philosophy \\
\hline & Music \\
\hline & Arts Humanities Other Topics \\
\hline & Religion \\
\hline & History Philosophy Of Science \\
\hline & Literature \\
\hline & History \\
\hline & Film Radio Television \\
\hline & Archaeology \\
\hline & Dance \\
\hline & Art \\
\hline Others & Science Technology Other Topics \\
\hline & Mathematics \\
\hline & Transportation \\
\hline & Food science technology \\
\hline & Medical Informatics \\
\hline & Acoustics \\
\hline
\end{tabular}




\begin{tabular}{|l|l|}
\hline \multirow{4}{|l|}{} & Agriculture \\
\cline { 2 - 3 } & Chemistry \\
\cline { 2 - 3 } & Mathematical Computational Biology \\
\cline { 2 - 3 } & Physics \\
\hline & Robotics \\
\hline & Materials Science \\
\hline & Optics \\
\hline & Telecommunications \\
\hline Imaging Science Photographic Technology \\
\hline & Instruments Instrumentation \\
\hline & Automation Control Systems \\
\hline & Transplantation \\
\hline & Architecture \\
\hline & Construction Building Technology \\
\hline & Electrochemistry \\
\hline & Meteorology Atmospheric Sciences \\
\hline & Energy Fuels \\
\hline & Nuclear Science Technology \\
\hline & Polymer Science \\
\hline & Physical Geography \\
\hline & Geography \\
\hline
\end{tabular}

\section{Appendix 4: Complete list of all merged WoS subject categories for disciplines citing humanities articles.}

\begin{tabular}{|l|l|}
\hline Merged Category & ISI Subject Category \\
\hline Philosophy & Philosophy \\
\cline { 2 - 2 } & History Philosophy of Science \\
\hline \multirow{4}{*}{ History } & History \\
\cline { 2 - 2 } & Archaeology \\
\hline Literature & Linguistics \\
\hline Religion & Literature \\
\hline Arts Humanities Other Topics & Religion \\
& Arts Humanities Other Topics \\
\cline { 2 - 2 } & Theater \\
\cline { 2 - 2 } & Film Radio Television \\
\cline { 2 - 2 } & Classics \\
\cline { 2 - 2 } & Art \\
\cline { 2 - 2 } & Music \\
\hline Social Sciences & Cultural studies \\
\cline { 2 - 2 } & Social Sciences Other Subjects \\
\cline { 2 - 2 } & Communication \\
\cline { 2 - 2 } & Anthropology \\
\hline
\end{tabular}




\begin{tabular}{|c|c|}
\hline & Area Studies \\
\hline & Women Studies \\
\hline & Information Science Library Science \\
\hline & International Relations \\
\hline & Asian Studies \\
\hline & Urban Studies \\
\hline & Ethnic Studies \\
\hline & Public Administration \\
\hline & Biomedical Social Sciences \\
\hline & Social Work \\
\hline Psychology & Psychology \\
\hline Education Educational Research & Education Educational Research \\
\hline Business \& Economics & Business \& Economics \\
\hline \multirow[t]{4}{*}{ Medicine and health } & Public Environmental Occupational Health \\
\hline & Psychiatry \\
\hline & Cardiovascular System Cardiology \\
\hline & Neurosciences Neurology \\
\hline \multirow[t]{2}{*}{ Biology \& Life Sciences } & Immunology \\
\hline & Biochemistry Molecular Biology \\
\hline Computer science & Computer Science \\
\hline \multirow[t]{7}{*}{ Others } & Materials Science \\
\hline & Science Technology Other Topics \\
\hline & Chemistry \\
\hline & Physics \\
\hline & Agriculture \\
\hline & Food Science Technology \\
\hline & Geography \\
\hline
\end{tabular}

\section{References}

Armbruster, C. (2008). Access, Usage and Citation Metrics: What Function for Digital Libraries and Repositories in Research Evaluation? Social Science Research Network Working Paper Series, 128(Pt 6), 1407-17. SSRN.

Arolas, E. E., \& Ladrón-de-Guevar, F. G. (2012). Uses of explicit and implicit tags in social bookmarking. Journal of the American Society for Information Science and Technology, 63(2), 313-322.

Bar-Ilan, J, Haustein, S., Peters, I., Priem, J., Shema, H., \& Terliesner, J. (2012). Beyond citations: Scholars' visibility on the social Web. 17th International Conference on Science and Technology Indicators. 5-8 September, 2012 in Montreal, Quebec, Canada.

Bar-Ilan, J. (2012). JASIST 2001-2010. Bulletin of the American Society for Information Science and Technology, 24-28.

Becher, T., \& Trowler, P. (2001). Academic tribes and territories (2ed). Milton Keynes, UK: Open University Press.

Bedeian, A. G. (2005). Crossing Disciplinary Boundaries: A Epilegomenon for Lockett and McWilliams. Journal of Management Inquiry, 14(2), 151-155. 
Blecic, D. D. (1999). Measurements of journal use: an analysis of the correlations between three methods. Bulletin of the Medical Library Association, 87(1), 20-5.

Bollen, J., Van De Sompel, H., Hagberg, A., \& Chute, R. (2009). A principal component analysis of 39 scientific impact measures. (T. Mailund, Ed.) PLoS ONE, 4(6), e6022.

Bollen, J., Van De Sompel, H., Smith, J. A., \& Luce, R. (2005). Toward alternative metrics of journal impact: A comparison of download and citation data. Information Processing \& Management, 41(6), 1419-1440.

Bordons, M., Morillo, F., \& Gómez, and I. (2005). analysis of cross-disciplinary research through bibliometric tools. In Henk F. Moed (Ed.), Handbook of Quantitative Science and Technology Research (pp. 437-456). Kluwer Academic Publishers.

Borrego, A. \& Fry, J. (2012). Measuring researchers' use of scholarly information through social bookmarking data: A case study of BibSonomy. Journal of Information Science, 38(3), 297 308.

Brody, T., Harnad, S., \& Carr, L. (2006). Earlier Web Usage Statistics as Predictors of Later Citation Impact. Journal of the American Society for Information Science and Technology, 57(8), 10601072.

Butler, L. (2003). Explaining Australia's increased share of ISI publications-the effects of a funding formula based on publication counts. Research Policy, 32(1), 143-155.

Cohen, J. (1988). Statistical power analysis for the behavioral sciences. (L. Erlbaum, Ed.)Statistical Power Analysis for the Behavioral Sciences (Vol. 2nd, p. 567). Lawrence Erlbaum Associates.

Cronin, B., \& Meho, L. (2007). The shifting balance of intellectual trade in information studies. Journal of the American Society for Information Science and Technology, 59(4), 551-564. Cronin, B., \& Pearson, S. (1990). The export of ideas from information science. Journal of Information Science, 16(6), 381-391.

Ding, Y., Jacob, E. K., Zhang, Z., Foo, S., Yan, E., George, N. L., \& Guo, L. (2009). Perspectives on social tagging. Journal of the American Society for Information Science and Technology, 60(12), 2388-2401.

Eysenbach, G. (2011). Can Tweets Predict Citations? Metrics of Social Impact Based on Twitter and Correlation with Traditional Metrics of Scientific Impact. Journal of Medical Internet Research, 13(4), e123.

Garfield, E. (2011). Full Text downloads and citations: Some reflections. Keynote lecture at the Seminar "Scientific Measurement and Mapping." Santa Fe, New Mexico.

Gingras, Y., \& Larivière, V. (2010). The historical evolution of interdisciplinarity: 1900-2008. Eleventh International Conference on Science and Technology Indicators. Leiden.

Goldstone, R. L., \& Leydesdorff, L. (2006). The import and export of cognitive science. Cognitive science, 30(6), 983-93.

Hahn, K., \& Faulkner, L. (2002). Evaluative Usage-based Metrics for the Selection of E-journals. College \& Research Libraries, 215-227.

Haque, A., \& Ginsparg, P. (2009). Positional effects on citation and readership in arXiv. Journal of the American Society for Information Science and Technology, 60(11), 2203-2218.

Haustein, S., \& Siebenlist, T. (2011). Applying social bookmarking data to evaluate journal usage. Journal of Informetrics, 5(3), 446-457.

Huang, M., \& Chang, Y. (2008). Characteristics of research output in social sciences and humanities: From a research evaluation perspective. Journal of the American Society for Information Science and Technology, 59(11), 1819-1828.

Krueckeberg, D. A. (1985). The Tuition of American Planning From Dependency toward SelfReliance. The Town Planning Review, 56(4), 421-441..

Jiang, J., He, D., \& Ni, C. (2011). Social Reference: Aggregating Online Usage of Scientific Literature in CiteULike for Clustering Academic Resources. JCDL'11 June 13-17 2011 (Vol. 11, pp. 401-402). Ottawa, Ontario, Canada: ACM.

Kraker, P., Körner, C., Jack, K., \& Granitzer, M. (2012). Harnessing user library statistics for research evaluation and knowledge domain visualization. Proceedings of the 21 st international conference companion on World Wide Web (pp. 1017-1024).

Kurtz, M., \& Bollen, J. (2010). Usage bibliometrics. Annual Review of Information Science and Technology, 44(1-64). 
Kurtz, M. J., Eichhorn, G., Accomazzi, A., Grant, C., Demleitner, M., Murray, S. S., Martimbeau, N., et al. (2005). The bibliometric properties of article readership information. Journal of the American Society for Information Science and Technology, 56(2), 111-128.

Kyvik, S. (2003). Changing trends in publishing behaviour among university faculty, 1980-2000. Scientometrics, 58, 35-48.

Levitt, J., \& Thelwall, M. (2011). Variations between subjects in the extent to which the social sciences have become more interdisciplinary. Journal of the American Society for Information Science and Technology, 62, 1118-1129.

Li, X, \& Thelwall, M. (2012). F1000 , Mendeley and Traditional Bibliometric Indicators. 17th International Conference on Science and Technology Indicators (Vol. 3, pp. 1-11).

Li, X., Thelwall, M., \& Giustini, D. (2012). Validating online reference managers for scholarly impact measurement, Scientometrics, 91(2), 461-471.

Lockett, A., \& McWilliams, A. (2005). The Balance of Trade Between Disciplines: Do We Effectively Manage Knowledge? Journal of Management Inquiry, 14(2), 139-150.

Leydesdorff, L., Carley, S., \& Rafols, I. (2013). Global maps of science based on the new Web-ofScience categories. Scientometrics, 94(2), 589-593.

Mark Ware Consulting. (2008). Peer review in scholarly journals: Perspective of the scholarly community an international study. Information Services and Use - APE 2008 Academic Publishing in Europe, Quality and Publishing, 28(2), 109-112. 9.

Moed, H F. (2005). Citation analysis in research evaluation (Vol. 9). Kluwer Academic Pub.

Moed, H F., Linmans, J., \& Nederhof, A. (2009). Options for a comprehensive database of research outputs in Social Sciences \& Humanities.

Morillo, F., Bordons, M., \& Gómez, I. (2003). Interdisciplinarity in science: A tentative typology of disciplines and research areas. Journal of the American Society for Information Science and Technology, 54(13), 1237-1249.

Nederhof, A. J., Zwaan, R. A., Bruin, R. E., \& Dekker, P. J. (1989). Assessing the usefulness of bibliometric indicators for the humanities and the social and beha vioural sciences: A comparative study. Scientometrics, 15(5-6), 423-435.

Nederhof. (2006). Bibliometric monitoring of research performance in the Social Sciences and the Humanities: A Review. Scientometrics, 66(1), 81-100. Neeley, J. D. (1981). The management and social science literatures: An interdisciplinary cross-citation analysis. Journal of the American Society for Information Science, 32(3), 217-223.

Neylon, C., \& Wu, S. (2009). Article-level metrics and the evolution of scientific impact. PLoS biology, 7(11), e1000242.

Pair, C. (1980). Switching between academic disciplines in universities in the Netherlands. Scientometrics, 2(3), 177-191.

Pierce, S. J. (1999). Boundary crossing in research literatures as a means of interdisciplinary information transfer. Journal of the American Society for Information Science, 50(3), 271-279.

Priem, J., \& Hemminger, B. M. H. (2010). Scientometrics 2.0: New metrics of scholarly impact on the social Web. First Monday, 15(7).

Priem, J., Groth, P., \& Taraborelli, D. (2012). The Altmetrics Collection. PLoS ONE, 7(11), e48753.

Priem, J., Piwowar, H. A., \& Hemminger, B. M. (2012). Altmetrics in the wild: Using social media to explore scholarly impact. Arxiv preprint arXiv:1203.4745.

Priem, J., Taraborelli, D., Groth, P., \& Neylon, C. (2011). alt-metrics: A manifesto (v 1.01 September 28, 2011: removed dash in alt-metrics). http://altmetrics.org/manifesto.

Rinia, E. . (2007). Measurement and evaluation of interdisciplinary research and knowledge transfer. Universiteit Leiden, The Netherlands.

Rinia, E. J., Van Leeuwen, T. N., Bruins, E. E. W., Van Vuren, H. G., \& Van Raan, A. F. J. (2001). Citation delay in interdisciplinary knowledge exchange. Scientometrics, 51(1), 293-309.

Rinia, Van Leeuwen, T., Bruins, E., Van Vuren, H., \& Van Raan, A. (2002). Measuring knowledge transfer between fields of science. Scientometrics, 54(3), 347-362.

Rowlands, I., \& Nicholas, D. (2005). Scholarly communication in the digital environment: The 2005 survey of journal author behaviour and attitudes. Aslib Proceedings, 57(6), 481-497.

Rowlands, I., \& Nicholas, D. (2007). The missing link: journal usage metrics. Aslib Proceedings, $59(3), 222-228$. 
Schloegl, C., \& Gorraiz, J. (2010). Comparison of citation and usage indicators: the case of oncology journals. Scientometrics, 82(3), 567-580.

Schloegl, C., \& Gorraiz, J. (2011). Global usage versus global citation metrics: The case of pharmacology journals. Journal of the American Society for Information Science and Technology, 62(2005), 161-170.

Schloegl, C., \& Gorraiz, J. (2011). Global usage versus global citation metrics: The case of pharmacology journals. Journal of the American Society for Information Science and Technology, 62(2005), 161-170.

Schloegl, C., \& Stock, W. G. (2004). Impact and relevance of LIS journals: A scientometric analysis of international and German-language LIS journals - Citation analysis versus reader survey. Journal of the American Society for Information Science and Technology, 55(13), 1155-1168.

Stevens, G. (1990). An Alliance Confirmed Planning Literature and the Social Sciences. Journal of the American Planning Association, 56(3), 341-349.

Tang, R. (2005). Evolution of the interdisciplinary characteristics of information and library science. Proceedings of the American Society for Information Science and Technology, 41(1), 54-63.

Thelwall, M. (2012). Journal impact evaluation: a webometric perspective. Scientometrics, 92(2), 429441.

Urata, H. (1990). Information flows among academic disciplines in Japan. Scientometrics, 18(3-4), 309-319.

Zhang, L., Glänzel, W., \& Liang, L. (2009). Tracing the role of individual journals in a cross-citation network based on different indicators. Scientometrics, 81(3), 821-838. 